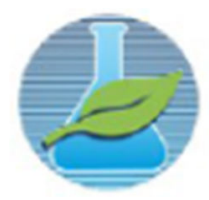

Vol. 02 N. 04 (2016) 052-054
$\mathrm{JCEC} / \mathrm{REQ}^{2}$

Journal

ISSN: 2446-9416

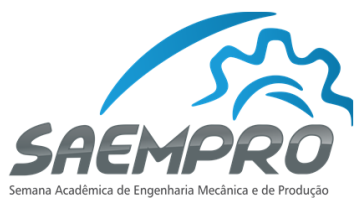

\author{
"EU, A INDÚSTRIA E O MUNDO" \\ 08 a 11 de novembro de 2016 no campus Viçosa da UFV \\ Departamento de Engenharia de Produção e Mecânica - DEP \\ Universidade Federal de Viçosa - UFV
}

\title{
PROCESSO DE FABRICAÇÃO DE UM CARRINHO DE ROLIMÃ
}

\author{
André Scalzer Frederico, Gabriela Pereira Toledo, Mateus Vidal de Vasconcelos Barros, \\ Lucas Benini \\ Universidade Federal de Viçosa - Departamento de Engenharia de Produção e Mecânica \\ Avenida Peter Henry Rolfs, s/n - Campus Universitário - 36570-000 - Viçosa - MG \\ andre.frederico@ufv.br, gabriela.toledo@ufv.br, lucas.benini@ufv.br
}

\section{INTRODUÇÃO}

Estre trabalho apresenta o processo de construção de um "carrinho de rolimã". Este carro geralmente e feito para uso recreativo, transportando uma única pessoa. O nome "carrinho de rolimã" se dá pelo uso de rolamentos como rodas. O objetivo da construção desse veículo foi inserir os estudantes no tópico de gerenciamento de projetos, para posteriormente os envolvidos possam aplicar este conhecimento no desenvolvimento de um veículo do tipo Formula Student para competições regidas pela SAE (Associação de Engenheiros Automotivos).

\section{METODOLOGIA}

De acordo com Costa (2016) o processo de gerenciamento de projeto é dividido em planejamento, execução, monitoramento e controle e por fim encerramento. Com base neste autor, o processo de construção do "carrinho de rolimã" foi dividido em três etapas: projeto conceitual, manufatura e testes. Esta divisão foi feita para facilitar a organização do processo como um todo.

\subsection{Projeto conceitual}

Nessa etapa foram definidas as dimensões do carro, os materiais utilizados e planejados os desdobramentos desde a manufatura até os testes no protótipo. As principais dimensões foram baseadas na ergonomia de pessoas entre a faixa de 1,60 m 1,80 m de altura, visando a dirigibilidade, o conforto e a segurança durante a condução.

Baseado nestes fatores o projeto de cada componente foi efetuado no software SolidWorks ${ }^{\circledR}$, conforme pode ser observado na Fig. 1. Os materiais empregados foram a madeira (utilizada na base, nos eixos, no freio e no encosto do piloto) e o aço (utilizado nos rolamentos e nos apoios de mão). A definição dos materiais foi baseada no custo, peso e dificuldade de manuseio. $\mathrm{O}$ carro foi projetado com o intuído de ser montado em um único dia, partindo da preparação dos componentes até a montagem dos mesmos, para isso foram selecionadas as ferramentas que seriam necessárias e como seria realizada cada tarefa. Ao final desta etapa foi elaborado o orçamento das ferramentas, das máquinas, das matérias primas e dos equipamentos de segurança.

\subsection{Manufatura}

Durante a fabricação ocorreram alguns imprevistos que alteraram algumas decisões definidas na etapa de projeto. A madeira tipo cedrinho que seria utilizada na base para o piloto não foi disponibilizada pelo fornecedor. Por este motivo foi necessário utilizar uma madeira alternativa, tipo angelim pedra, sendo mais pesada e com mais alto custo em relação a madeira inicialmente selecionada. 


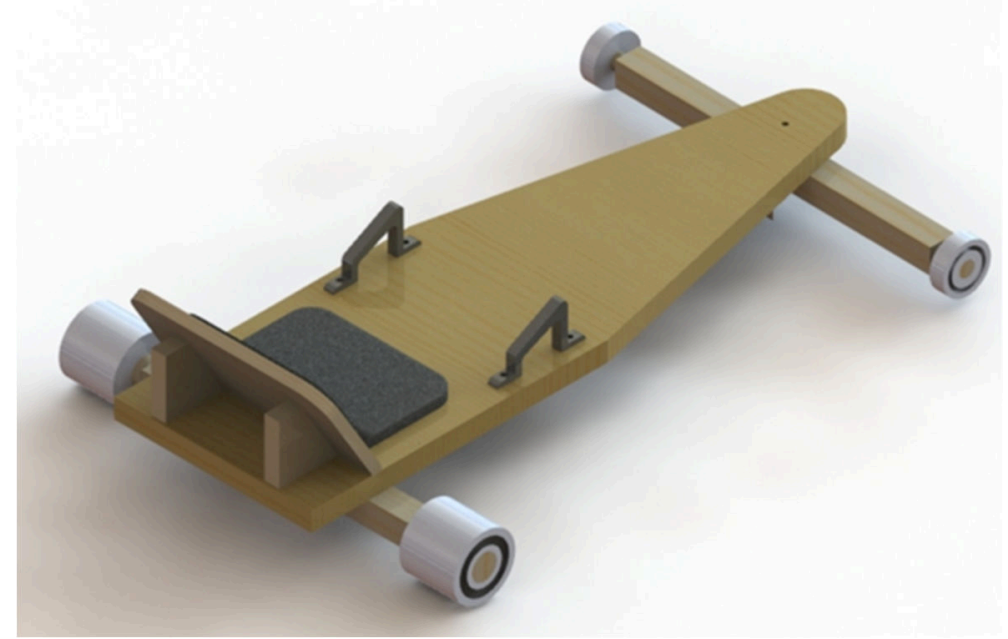

Figura 1 - Desenho CAD do carinho de rolimã.

Tal cenário acarretou na alteração das medidas iniciais definidas no intuito de reduzir peso e custos. Outro fator que influenciou o resultado final do protótipo foi o projeto do freio: durante a manufatura do freio foi verificado que o design projetado era ineficiente e de difícil construção, sendo este alterado para um tipo menos complexo e eficiente. A Fig. 2 mostra a etapa de fabricação do carrinho de rolimã.

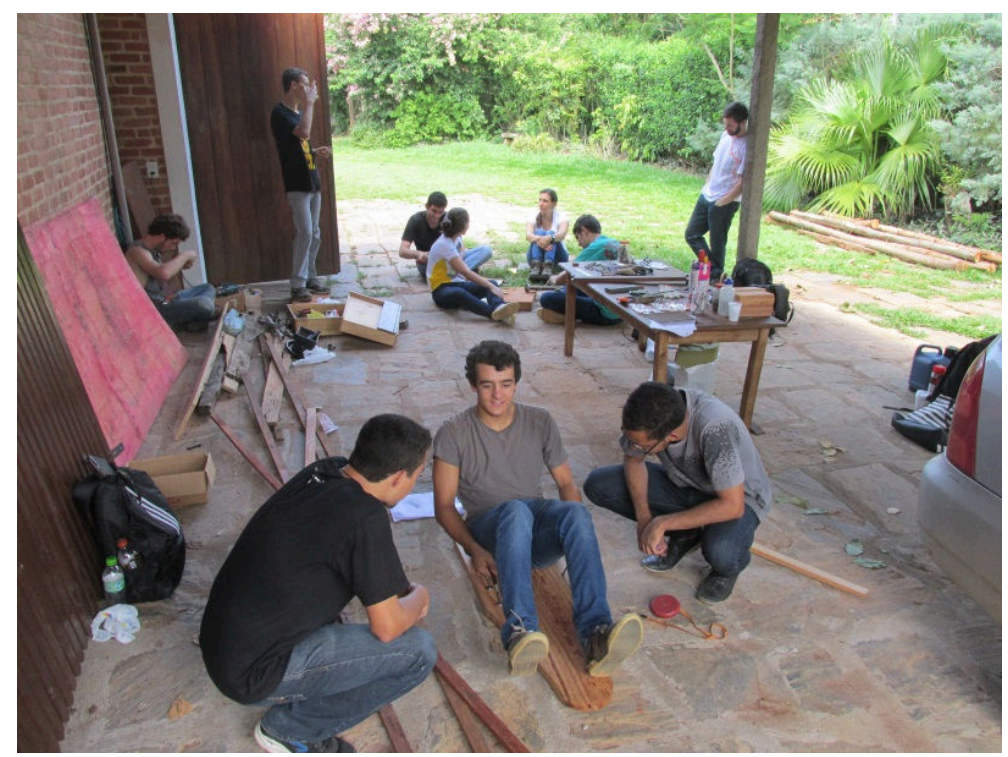

Figura 2 - Manufatura do carrinho de rolimã.

\subsection{Validação}

Após a finalização da fabricação do carrinho de rolimã (Fig. 3) foram efetuados o teste de estabilidade. O teste ocorreu em uma via inclinada dentro da Universidade Federal de Viçosa, onde carro se movimentou do ponto mais alto da via até a parte inferior, apenas sob a influência dos pesos do piloto e do carrinho. Foram feitos cinco testes partindo de alturas diferentes pare se verificar as velocidades máximas do carinho e o funcionamento do freio em cada caso.

Durante o teste um dos rolamentos se soltou do eixo devido a folga entre o eixo e o rolamento. Foi realizada uma manutenção corretiva que consistiu em acrescentar um parafuso no eixo, para o aumento de seu diâmetro externo. 


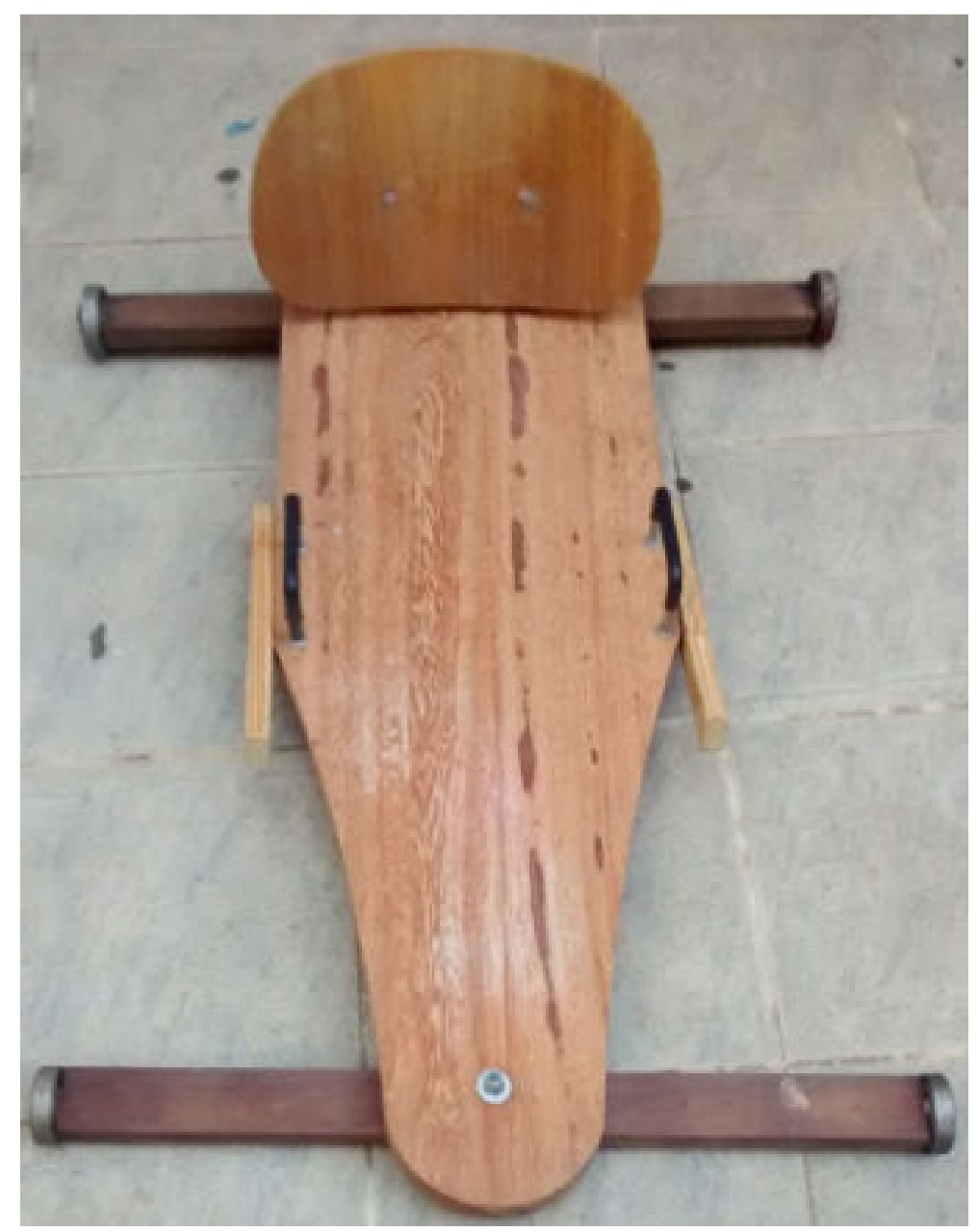

Figura 3 - Resultado final do produto.

\section{CONSIDERAÇÕES FINAIS}

A partir da realização do processo de fabricação do carrinho de rolimã os envolvidos adquiriram conhecimentos relacionados ao gerenciamento de projetos que foram aplicados em outras atividades realizadas pelos alunos envolvidos neste projeto. Pode-se citar o desenvolvimento do protótipo do carro tipo Fórmula. Destaca-se a importância do gerenciamento de tempo nas fases do projeto. É de extrema importância determinar o tempo necessário para que cada tarefa seja cumprida de forma eficiente.

Além disso, notou-se que desenvolver um projeto conceitual detalhado e eficaz é fundamental para uma manufatura eficiente. Por fim, verificou-se a importância da realização de testes de validação para verificar o funcionamento do produto em diferentes situações.

\section{AGRADECIMENTOS}

Aos integrantes da equipe Fórmula Majorados pela dedicação ao projeto da construção do carrinho de rolimã.

\section{REFERÊNCIAS}

COSTA, D. "Aplicação de conceitos de gestão de projetos relacionados ao modelo stage-gate: o caso do projeto Fórmula SAE”. Niterói, RJ, 2016.

FERREIRA, M. "Utilização de modelos para a representação de produtos no projeto conceitual". Dissertação (Mestrado em Engenharia) - Universidade Federal de Santa Catarina. Florianópolis, SC. 1997. 